\title{
Correction to: Algorithm for the management of patients at low, high and very high risk of osteoporotic fractures
}

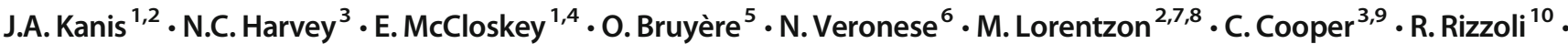 \\ G. Adib ${ }^{11} \cdot$ N. Al-Daghri ${ }^{12}$ - C. Campusano ${ }^{13} \cdot$ M. Chandran ${ }^{14}$ - B. Dawson-Hughes ${ }^{15} \cdot$ K. Javaid ${ }^{9} \cdot$ F. Jiwa ${ }^{16}$. $^{12}$ \\ H. Johansson ${ }^{1,2} \cdot$ J.K. Lee ${ }^{17}$ - E. Liu ${ }^{2}$ - D. Messina ${ }^{18}$ - O. Mkinsi ${ }^{19}$ - D. Pinto ${ }^{20,21}$ - D. Prieto-Alhambra ${ }^{9,22} \cdot$ K. Saag $^{23}$. \\ W. Xia ${ }^{24} \cdot$ L. Zakraouii ${ }^{25} \cdot$ J.Y. Reginster ${ }^{12,26}$
}

Published online: 17 February 2020

(C) The Author(s) 2020

\section{Correction to: Osteoporosis International, https://doi.org/10.1007/s00198-019-05176-3}

The article 'Algorithm for the management of patients at low, high and very high risk of osteoporotic fractures', written by J. A. Kanis, was originally published Online First without Open Access. After publication in volume [\#], issue [\#] and page [\#-\#], the author decided to opt for Open Choice and to make the article an Open Access publication. Therefore, the copyright of the article has been changed to (C) The Author(s) (2019) and the article is forthwith distributed under the terms of a Creative Commons Attribution-NonCommercial 4.0 International License (https://creativecommons.org/licenses/ by-nc/4.0/), which permits any non-commercial use, sharing, adaptation, distribution, and reproduction in any medium or format, as long as you give appropriate credit to the original author(s) and the source; provide a link to the Creative Commons licence and indicate if changes were made.
The original article has been corrected.

Open Access This article is licensed under a Creative Commons Attribution-NonCommercial 4.0 International License, which permits any non-commercial use, sharing, adaptation, distribution and reproduction in any medium or format, as long as you give appropriate credit to the original author(s) and the source, provide a link to the Creative Commons licence, and indicate if changes were made. The images or other third party material in this article are included in the article's Creative Commons licence, unless indicated otherwise in a credit line to the material. If material is not included in the article's Creative Commons licence and your intended use is not permitted by statutory regulation or exceeds the permitted use, you will need to obtain permission directly from the copyright holder. To view a copy of this licence, visit http:// creativecommons.org/licenses/by-nc/4.0/.

The online version of the original article can be found at https://doi.org/ 10.1007/s00198-019-05176-3

J.A. Kanis

w.j.Pontefract@shef.ac.uk

Extended author information available on the last page of the article 


\section{Affiliations}

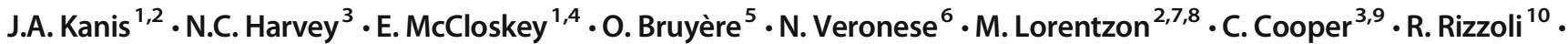

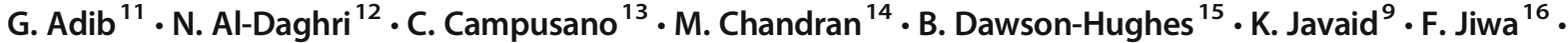

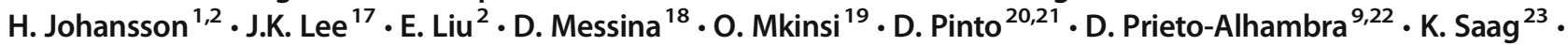
W. Xia ${ }^{24} \cdot$ L. Zakraoui ${ }^{25} \cdot$ J.Y. Reginster ${ }^{12,26}$

1 Centre for Metabolic Bone Diseases, University of Sheffield Medical School, Beech Hill Road, Sheffield S10 2RX, UK

2 Mary McKillop Health Institute, Australian Catholic University, Melbourne, Australia

3 MRC Lifecourse Epidemiology Unit, University of Southampton, Southampton, UK

$4 \quad$ MRC and Arthritis Research UK Centre for Integrated Research in Musculoskeletal Ageing Mellanby, Sheffield, UK

5 World Health Organization Collaborating Center for the Public Health Aspects of Musculoskeletal Health and Aging, Department of Public Health, Epidemiology and Health Economics, University of Liège, Liège, Belgium

6 National Research Council, Neuroscience Institute, Aging Branch, Via Giustiniani 2, 35128 Padova, Italy

7 Geriatric Medicine, Department of Internal Medicine and Clinical Nutrition, Institute of Medicine and Clinical Nutrition, Sahlgrenska Academy, University of Gothenburg, Gothenburg, Sweden

8 Region Västra Götaland, Geriatric Medicine Clinic, Sahlgrenska University Hospital, Gothenburg, Sweden

9 NIHR Musculoskeletal Biomedical Research Unit, University of Oxford, Oxford, UK

10 Service of Bone Diseases, Geneva University Hospitals and Faculty of Medicine, Geneva, Switzerland

11 Syrian National Osteoporosis Society, Damascus, Syria

12 Biochemistry Department, College of Science, King Saud University, Riyadh, Kingdom of Saudi Arabia

13 Clinica Universidad de los Andes and Faculty of Medicine, Universidad de los Andes, Santiago, Chile
Osteoporosis and Bone Metabolism Unit, Department of Endocrinology, Singapore General Hospital, ACADEMIA, 20, College Road, Singapore 169856, Singapore

15 Jean Mayer USDA Human Nutrition Research Center on Aging, Tufts University, Boston, MA, USA

16 International Osteoporosis Foundation, Osteoporosis Canada, Toronto, Canada

17 Beacon International Specialist Centre, Petaling Jaya, Malaysia

18 IRO Medical Research Center, Buenos Aires and Rheumatology Section, Cosme Argerich, Buenos Aires, Argentina

19 Department of Rheumatology, Ibn Rochd University Hospital, Casablanca, Morocco

20 Department of Physical Therapy, Marquette University, Milwaukee, WI, USA

21 Department of Medical Social Sciences, Feinberg School of Medicine, Northwestern University, Chicago, IL, USA

22 GREMPAL Research Group, CIBERFes and Idiap Jordi Gol, Instituto de Salud Carlos III and Universitat Autonoma deBarcelona, Barcelona, Spain

23 University of Alabama at Birmingham, Birmingham, AL, USA

24 Department of Endocrinology, Key Laboratory of Endocrinology, Ministry of Health, Peking Union Medical College Hospital, Chinese Academy of Medical Sciences \& Peking Union Medical College, Shuaifuyuan No. 1, Wangfujing, Dongcheng District, Beijing 100730, China

25 Service de Rhumatologie, University Tunis Manar and HôpitalMongi-Slim, la Marsa, Tunisia

26 Department of Public Health, Epidemiology and Health Economics, University of Liège, Liège, Belgium> 